\title{
Mitigation of corrosion of carbon steel in acidic solutions using an aqueous extract of Tilia cordata as green corrosion inhibitor
}

\author{
A. S. Fouda ${ }^{1}$ - A. S. Abousalem ${ }^{1}$ - G. Y. EL-Ewady ${ }^{1}$
}

Received: 21 September 2015/ Accepted: 7 November 2016/Published online: 18 November 2016

(c) The Author(s) 2016. This article is published with open access at Springerlink.com

\begin{abstract}
The effectiveness of using Tilia cordata extract as a green corrosion inhibitor for carbon steel in $1 \mathrm{M}$ hydrochloric acid solutions was demonstrated by employing some chemical and electrochemical techniques. The surface morphology of C-steel specimens was examined. The results showed that Tilia cordata has corrosion inhibition characteristics with efficiency of $96 \%$ as the concentration of Tilia cordata extract increased to $300 \mathrm{mg} \mathrm{L}^{-1}$. Charge transfer resistance $\left(R_{\mathrm{ct}}\right)$ value increases while both the capacitance of the double layer $\left(C_{\mathrm{dl}}\right)$ and corrosion current $\left(i_{\text {corr }}\right)$ values decrease with increasing the extract concentration. The effect of temperature was studied in the range $30-60{ }^{\circ} \mathrm{C}$. Some thermodynamic parameters were calculated and discussed. The adsorption of extract on the C-steel surface was found to obey Langmuir adsorption isotherm. Polarization results showed that the investigated extract acts as mixed type inhibitor. All the different used techniques gave similar results.
\end{abstract}

Keywords Corrosion inhibition $\cdot \mathrm{HCl} \cdot \mathrm{C}$-steel $\cdot$ Tilia cordata extract · Adsorption

\section{Introduction}

Corrosion is the process whereby metals and alloys lose their useful properties as a result of a reaction with the surrounding environment. The definition of corrosion is not

A. S. Abousalem

ashraf.abousalem@gmail.com

1 Chemistry Department, Faculty of Science, Mansoura University, Mansoura 35516, Egypt limited to metals and alloys, but the term, corrosion, can be extended to include ceramics and other nonmetallic materials. Corrosion leads to major problems in most industrial fields [1]. In the recent years, corrosion becomes one of the most challenging topics for scientists and the engineering society. From the standpoint of the importance of metals in industry, carbon steel is considered to be the metal of choice due to its distinctive characteristics, besides the wide application aspects. In several industrial processes such as acid cleaning, acid well acidizing, and acid pickling, rust and contaminated scales were generally removed using acid solutions. Moreover, hydrochloric acid can be produced as a byproduct of crude oil desalting process and some oil refinery treatments [2]. Hydrochloric and sulphuric acids are the most widely used mineral acids in the pickling processes of metals [3]. It is generally known that the spontaneous dissolution of iron in acid solution produces $\mathrm{Fe}^{2+}$ ions, which corresponds to the anodic reaction, accompanied by discharging of electrons by hydrogen evolution at cathodic sites on the metal surface. Because of the general destructive attack of acid solutions, the use of inhibitors to control the aggressiveness of acid environment was found to have widespread applications in many industries [4]. The feasibility of protection methods depend mainly on the conditions and surrounding environment that materials, particularly metals, experienced during service conditions. The use of corrosion inhibitor to minimize corrosion rate in closed service system is well-established and generally accepted [5-8]. In literature, several organic compounds have been reported as potential corrosion inhibitor for different metals, but on the other hand, ecological and healthy problems have been arisen because of using such synthetic compounds. In recent years, considerable amount of effort devoted to find low cost and efficient corrosion inhibitors from natural resources such as 
plant extracts that can be used as promising alternative sources for corrosion inhibitors [9-12]. Several studies reports the use of plant extracts as potential agents to reduce corrosion in various industrial solutions [13-15]. Inhibitors extracted from plants are renewable resources, readily available, acceptable and friendly for human and environment [11]. To our knowledge, there seems no results have been reported in the literature for using Tilia cordata as corrosion inhibitor. The present work provide an investigation on using an aqueous extract, simply prepared from the leaves of Tilia cordata, as a green corrosion inhibitor to control the corrosion behavior of carbon steel in hydrochloric acid solutions.

\section{Materials and methods}

\section{Specimen preparation}

The carbon steel used in the present study was brought from Nile Delta Fields, Petrobel Company, Abu-Mady in Egypt. The chemical composition of the material (wt \%) is as follows; C (0.17-0.20), Mn (0.35), P (0.025), Si (0.003) and $\mathrm{Fe}$ (balance). For weight loss measurements, a rectangle sheet of carbon steel was mechanically cut to prepare seven specimens, each of identical dimensions, $20 \times 20 \times 1 \mathrm{~mm}$. A small hole with a diameter $2 \mathrm{~mm}$ was punched at one top corner of each specimen. Glass hooks were used to hold the specimens in the test solutions.

\section{Solution preparation}

Analar grade reagents and bi-distilled water were used for the acid solution preparation. The test solution was $1 \mathrm{M}$ $\mathrm{HCl}$. The hydrochloric acid was purchased from AlGomhoria Co. for chemicals, in Egypt. A volume of $100 \mathrm{ml}$ of $\mathrm{HCl}$ solutions was freshly prepared and used as test solution before each experiment.

\section{Preparation of plant extract}

The investigated plant was purchased from "Al Nakyti" a local plant supplier in Egypt. The studied aqueous extract was prepared from the leaves of Tilia cordata. The leaves were air-dried, grinding down to small pieces. A sample of $150 \mathrm{~g}$ of grinded leaves was added to $250 \mathrm{ml}$ of bi-distilled water in a conical flask of a volume $1000 \mathrm{ml}$, the mixture was boiled for $30 \mathrm{~min}$, and then cooled in dark place, after the extraction process, the crude extract was filtered using Whatman Filter Papers to remove undesirable solid residues and contamination. A volume of $10 \mathrm{ml}$ of the crude extract is taken out and desiccated at fixed temperature. The resultant desiccated solid residue is weighted to aid in determining the concentration of the aqueous extract. A stock solution of $1000 \mathrm{mg} \mathrm{L}^{-1}$ was prepared by taking $70 \mathrm{ml}$ of the crude extract and completed to $1000 \mathrm{ml}$ with bi-distilled water. The range of the plant extract concentration was as follows; 50-300 $\mathrm{mg} \mathrm{L}^{-1}$. Table 1 lists the proposed chemical structure of some phytochemical constituents isolated from a crude extract of Tilia cordata [16-19].

\section{Weight loss measurements}

The surface of carbon steel specimens were abraded, to a mirror finish, using different grades of emery paper starting with coarser type 80 to finer one 1200 , degreased with acetone, rinsed with bi-distilled water and gently dried using filter papers. The procedure of the experiment was as follows; first, the mass of specimens was measured precisely to 0.0001 digits by using a high sensitive electronic balance, and then the specimens were immersed into $100 \mathrm{ml}$ of $1 \mathrm{M}$ Hydrochloric acid solution in absence and presence of various concentrations of Tilia cordata extract at $30^{\circ} \mathrm{C}$. For weight loss experiment, the immersion time intervals were (30 min until $180 \mathrm{~min}$ ). After each interval time, the tested specimens were taken out of the solution, rinsed with bi-distilled water, thoroughly dried and the mass after immersion is precisely reweighted and recorded. The corrosion rate $\left(C_{\mathrm{R}}\right)$ in $\mathrm{mg} \mathrm{cm}^{-2} \mathrm{~min}^{-1}$ was calculated from the value of weight loss divided by the total surface area $\left(\mathrm{cm}^{2}\right)$ and immersion time (min).

\section{Electrochemical technique}

Three different electrochemical techniques were conducted using three electrode system assembled in a glass cell as follows; carbon steel specimen as working electrode $\left(1 \mathrm{~cm}^{2}\right)$, saturated calomel electrode (SCE) acts a reference electrode, and platinum wire serves as an auxiliary electrode. In the present work, the working electrode was made of squared specimen of carbon steel welded with copper rod from one side and totally encapsulated into a glass rod, of larger diameter $(5 \mathrm{~mm})$ so that only one face of the carbon steel specimen, of dimension $(1 \mathrm{~cm} \times 1 \mathrm{~cm})$, was left to be exposed to the test solution and act as the active working surface. The reference electrode was connected to a Luggin capillary and the tip of the Luggin capillary is set to be very close to the surface of the working electrode in order to partially eliminate error originated from IR drop. All the measurements performed were subjected to stagnant conditions. Before starting electrochemical experiments, the working electrode was prepared in the same manner of weight loss method and the electrode potential was stabilized for $20 \mathrm{~min}$. All electrochemical results were obtained using Gamry Instrument (PCI4/750) with a Gamry system based on the ESA400 and computerized frameworks include DC105 software for potentiodynamic 
Table 1 List of some phytochemical constituents isolated from a crude extract Tilia cordata

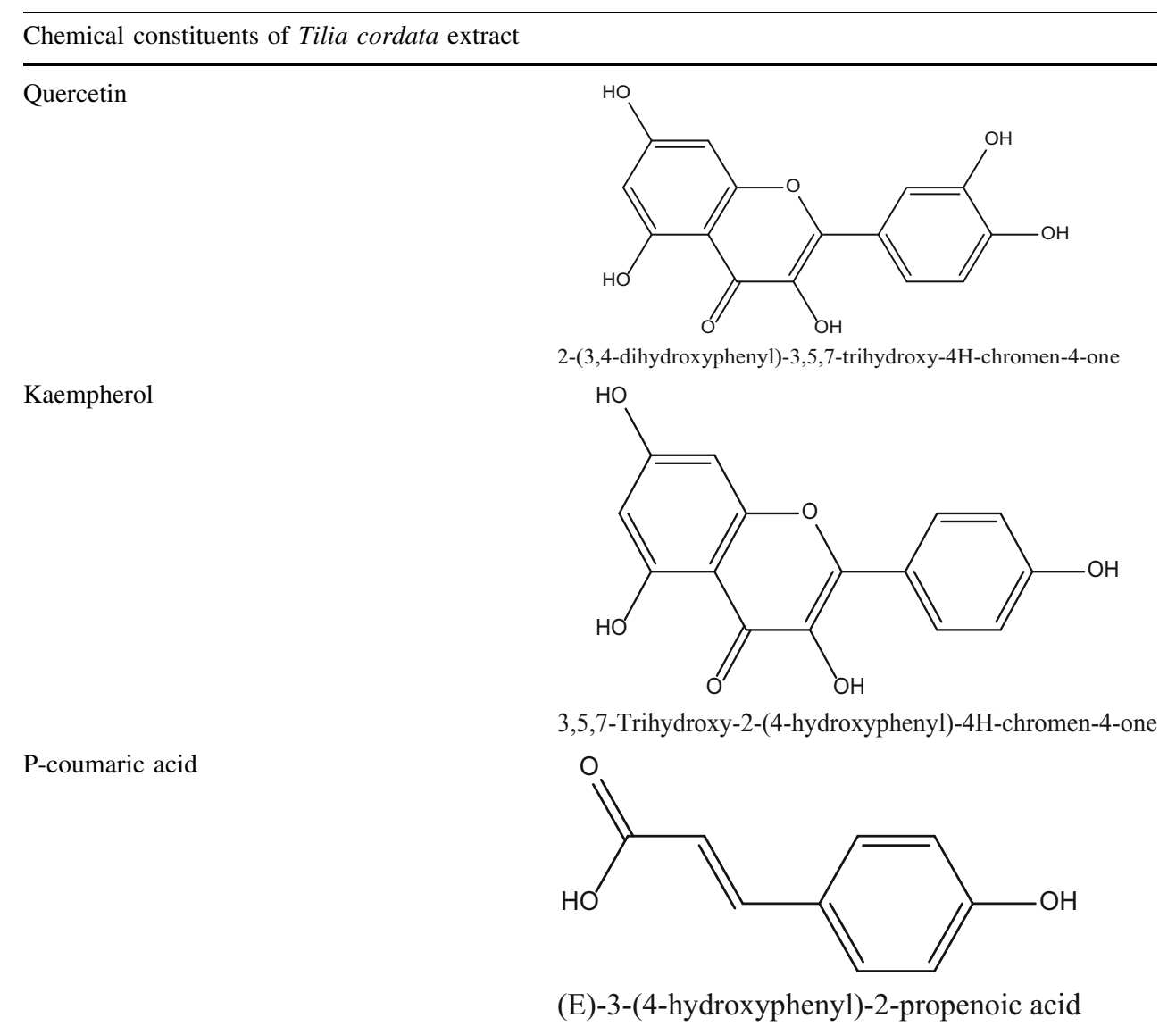

polarization measurements, EIS300 software for electrochemical impedance (ac) spectroscopy, and EFM140 software for electrochemical frequency modulation measurements. In addition, Echem Analyst 6.03 software was used for data fitting, graphing and plotting.

\section{Potentiodynamic polarization}

Tafel curves obtained from potential polarization scan by automatically sweeping the working electrode potential with a scan rate of $5 \mathrm{mVs}^{-1}$ from $(-700$ to $700 \mathrm{mV}$ vs. SCE) at open circuit potential. The corrosion current density was calculated by the extrapolation of cathodic and anodic Tafel lines $\left(\beta_{\mathrm{c}}\right.$ and $\left.\beta_{\mathrm{a}}\right)$ to an intersection that gives $\log i_{\text {corr }}$ and the relevant corrosion potential $\left(E_{\text {corr }}\right)$ for the free acid and each concentration of the investigated plant extract. The inhibition efficiency (\%IE) and surface coverage $(\theta)$ were calculated using the obtained values of $i_{\text {corr }}$.

\section{Electrochemical impedance spectroscopy}

EIS experiments were carried out at open circuit potential, alternative current signals, in frequency range from $100 \mathrm{kHz}$ to $0.5 \mathrm{~Hz}$ with amplitude of $10 \mathrm{mV}$ peak-to-peak, were applied to measure the impedance of the corrosion process. An equivalent electrical circuit was tested to explain the impedance results.

\section{Electrochemical frequency modulation}

Two different frequencies 2 and $5 \mathrm{~Hz}$ with base frequency equals to $0.1 \mathrm{~Hz}$ [20-22] were applied to obtain the intermodulation spectra of the electrochemical frequency modulation. It is necessary for the value of lower frequency to be not greater than a half of the higher frequency. The higher frequency must also be sufficiently slow that the charging of the double layer does not contribute to the current response. The current responses, obtained from EFM spectra, assigned for intermodulation and harmonical current peaks. The large peaks [23] function to calculate the corrosion current density $\left(i_{\text {corr }}\right)$, the slopes of Tafel curves $\left(\beta_{\mathrm{a}}\right.$ and $\left.\beta_{\mathrm{c}}\right)$ and corresponding causality factors $[\mathrm{CF}-$ 2 and $\mathrm{CF}-3]$.

\section{Surface analysis}

Three squared pieces of carbon steel specimens, of dimensions $(20 \times 20 \times 1 \mathrm{~mm})$, were used in this analysis, 
the first piece of metal was used to represent the carbon steel surface without neither exposure to acid nor treatment with extract inhibitor, the second specimen was completely immersed for $12 \mathrm{~h}$ into the free acid $(1 \mathrm{M} \mathrm{HCl})$ and without exposure to plant extract inhibitor. The third sample of metal was immersed for $12 \mathrm{~h}$ in a test solution of $1 \mathrm{M} \mathrm{HCl}$ containing $300 \mathrm{mg} \mathrm{L}^{-1}$ of Tilia cordata extract. The surface of these specimens was scanned and examined using scanning electron microscope (SEM, JOEL, JSMT20, Japan) and the elemental composition of carbon steel surface was detected using energy dispersive X-ray spectroscopy (EDX) Type: Philips X-ray diffractometer (pw1390) equipped with Cu-tube (Cu Ka1, $1=1.54051 \AA)$.

\section{Results and discussion}

\section{Weight loss measurements}

Weight loss in $\mathrm{mg}$ per $\mathrm{cm}^{2}$ was determined in laboratory after equal time interval of immersion into a test solution of $1 \mathrm{M} \mathrm{HCl}$ without and with treatment of various concentrations of the investigated additive. As shown in Fig. 1, curves for additive-containing systems fall below of the free acid. This suggests that the weight loss of carbon steel is a function of both the type and the concentration of the additive. The surface coverage, likewise, the inhibition efficiency increases when the concentration of the additive plant extract increases as indicated by the drop occurs in weight loss per $\mathrm{cm}^{2}$, while the inhibition efficiency decreases as the temperature of the test solution increases, this suggests electrostatic mode of adsorption (physical

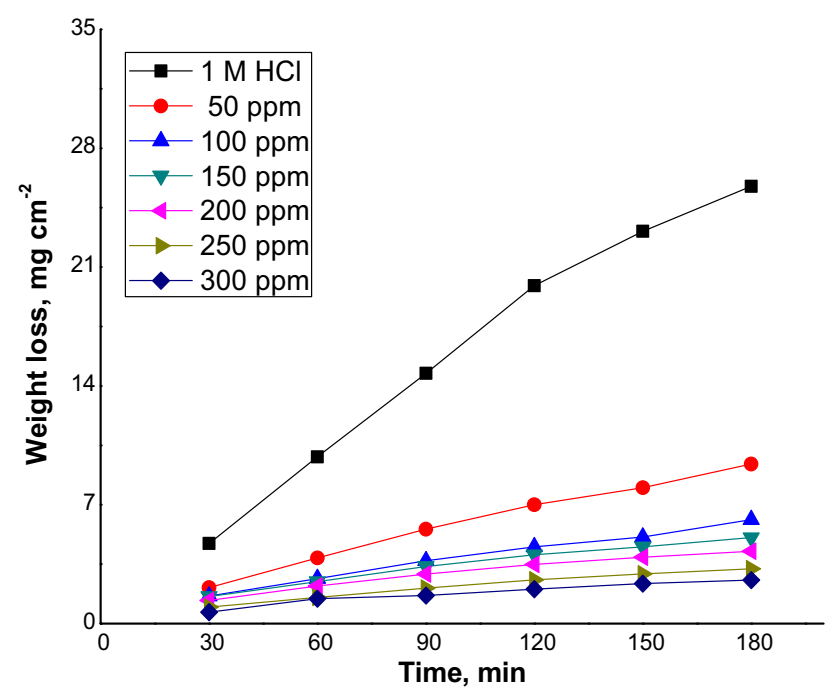

Fig. 1 Plots of mass loss vs. immersion time for carbon steel corrosion in $1 \mathrm{M} \mathrm{HCl}$ without and with the treatment of Tilia cordata extract at $30{ }^{\circ} \mathrm{C}$ adsorption) generating on the metal surface by the action of plant extract constituents. Table 2 lists the inhibition efficiency (\%IE) and the surface coverage $(\theta)$ obtained from weight loss calculation. The inhibition efficiency (\% IE) and the degree of surface coverage $(\theta)$ were calculated from Eq. (1):

$\% \mathrm{IE}=\theta \times 100=\left[\left(C_{\mathrm{R}}^{\prime}-C_{\mathrm{R}}\right) / C_{\mathrm{R}}^{\prime}\right] \times 100$,

where $\theta$ is the surface coverage, $C_{\mathrm{R}}^{\prime}, C_{\mathrm{R}}$ represent the corrosion rates in absence and presence of extract inhibitor, respectively.

\section{Adsorption isotherm}

Different mathematical representations were tested to obtain the best fit representing the adsorption isotherms. The studied corrosion inhibition system corresponds to Langmuir adsorption isotherm given by the following equation [24]:

$C / \theta=1 / k_{\mathrm{ads}}+C$,

where $\theta$ represents the surface coverage, $C$ is the concentration of the plant extract inhibitor and $K_{\text {ads }}$ is the equilibrium constant of adsorption related to the free energy of adsorption $\Delta G_{\text {ads }}^{\circ}$ by the following [25]:

$K_{\text {ads }}=1 / 5.55 \exp \left(-\Delta G_{\text {ads }}^{\circ} / \mathrm{RT}\right)$.

Straight lines obtained when plotting $C / \theta$ vs. $C$ for the adsorption of the plant additive on the surface of carbon steel in hydrochloric acid at $30{ }^{\circ} \mathrm{C}$ is shown in Fig. 2 and the adsorption of thermodynamic parameters were calculated and listed in Table 3. It can be seen that, $\Delta G_{\text {ads }}^{\circ}$ become less negative, in other meaning, increase when rising the temperature. This suggests that the adsorption process occurred by the electrostatic attraction. The negative values of $\Delta G_{\text {ads }}^{\circ}$ suggest that the adsorbed layer on the carbon steel surface is stable and the adsorption process is spontaneous [26]. The values of $\Delta G_{\text {ads }}^{\circ}$ were less negative than $-20 \mathrm{~kJ} \mathrm{~mol}^{-1}$ indicating that the adsorption mechanism of the investigated extract on carbon steel in $1 \mathrm{M} \mathrm{HCl}$ solution is consistent with physisorption $[27,28]$. The heat of adsorption $\left(\Delta H_{\mathrm{ads}}^{\circ}\right)$ could be calculated according to the Vant Hoff equation [29]:

$\log K_{\text {ads }}=\left(-\Delta H_{\text {ads }}^{\circ} / 2.303 \mathrm{RT}\right)+$ constant.

Log $K_{\text {ads }}$ was plotted against $1 / \mathrm{T}$ as shown in Fig. 3 to calculate the heat of adsorption $\Delta H_{\mathrm{ads}}^{\circ}$. The straight lines were obtained with slope equal to $\left(-\Delta H_{\text {ads }}^{\circ} / 2.303 \mathrm{R}\right)$. In consistence with the following equation [30]:

$\Delta G_{\mathrm{ads}}^{\circ}=\Delta H_{\mathrm{ads}}^{\circ}-\mathrm{T} \Delta S_{\mathrm{ads}}^{\circ}$. 
Table 2 The effect of different concentration of Tilia cordata extract on the corrosion rate $\left(C_{\mathrm{R}}\right)\left(\mathrm{mg} \mathrm{cm}^{2} \mathrm{~min}^{-1}\right)$ and inhibition efficiency $(\% \mathrm{IE})$ of carbon steel in $1 \mathrm{M} \mathrm{HCl}$ solution at different temperatures

\begin{tabular}{|c|c|c|c|c|c|c|}
\hline \multirow[t]{2}{*}[C_{\mathrm{inh}}]{$\left(\mathrm{mg} \mathrm{L}^{-1}\right)$} & \multicolumn{2}{|l|}{$30^{\circ} \mathrm{C}$} & \multicolumn{2}{|l|}{$40^{\circ} \mathrm{C}$} & \multicolumn{2}{|l|}{$50^{\circ} \mathrm{C}$} \\
\hline & $C_{\mathrm{R}}\left(\mathrm{mg} \mathrm{cm}^{-2} \mathrm{~min}^{-1}\right) \times 10^{-3}$ & $\% \mathrm{IE}$ & $C_{\mathrm{R}}\left(\mathrm{mg} \mathrm{cm} \mathrm{cm}^{-2} \mathrm{~min}^{-1}\right) \times 10^{-3}$ & $\% \mathrm{IE}$ & $C_{\mathrm{R}}\left(\mathrm{mg} \mathrm{cm}^{-2} \mathrm{~min}^{-1}\right) \times 10^{-3}$ & $\% \mathrm{IE}$ \\
\hline 0 & 165.8 & - & 275.8 & - & 398.4 & - \\
\hline 50 & 58.4 & 64.8 & 159.3 & 42.2 & 242.1 & 39.2 \\
\hline 100 & 37.7 & 77.2 & 106.6 & 61.3 & 171.7 & 56.9 \\
\hline 150 & 33.8 & 79.6 & 97.2 & 64.7 & 160.6 & 59.7 \\
\hline 200 & 29.0 & 82.5 & 73.5 & 73.3 & 152.4 & 61.7 \\
\hline 250 & 21.4 & 87.1 & 67.9 & 75.4 & 127.0 & 68.1 \\
\hline 300 & 16.9 & 89.8 & 64.8 & 76.5 & 99.8 & 74.9 \\
\hline
\end{tabular}

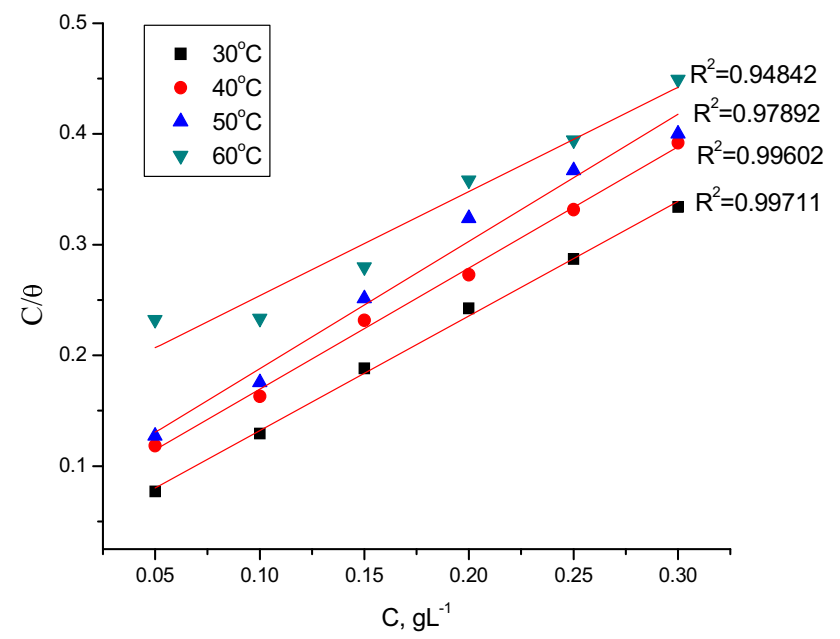

Fig. 2 Langmuir adsorption plots for carbon steel in $1 \mathrm{M} \mathrm{HCl}$ at different temperatures in the presence of various concentration of Tilia cordata extract

\section{Effect of temperature}

The influence of temperature, on the inhibition efficiency and nature of corrosion process, was explained by Arrhenius and transition state equations. Arrhenius equation:

$\log k_{\text {corr }}=-E_{\mathrm{a}}^{*} / 2.303 \mathrm{RT}+$ constant.

Transition state equation [31]:

Rate $\left(k_{\text {corr }}\right)=\mathrm{RT} / \operatorname{Nhexp}\left(\Delta S^{*} / R\right) \exp \left(-\Delta H^{*} / \mathrm{RT}\right)$.
The average value of corrosion rate $\left(k_{\text {corr }}\right)$ obtained from weight loss experiment at different temperatures was used to study the effect of temperature. According to Arrhenius equation, the values of $\log k_{\text {corr }}$ were plotted vs. $1 / T$. The resultant curves were straight lines with slopes $\left(-E_{\mathrm{a}}^{*} / 2.303\right.$ $\mathrm{R})$, from which the activation energy of the process can be calculated $\left(E_{\mathrm{a}}^{*}\right)$. Likewise, straight lines were obtained when plotting the values of $\log \left(k_{\text {corr }} / T\right)$ vs. $1 / T$ as shown in Fig. 5. According to the transition state equation, the slope of these curves equal $\left(-\Delta H^{*} / 2.303 R\right)$ and the intercept is $\left[(\log (R / \mathrm{Nh}))+\left(\Delta S^{*} / 2.303 R\right)\right]$, from which the values of $\Delta H^{*}$ and $\Delta S^{*}$ were determined and listed in Table 4. The results in Table 4 indicate that the activation energy increased in presence of extract than in case of free acid solution. This indicates that the extract molecules adsorbed physically on carbon steel surface. By increasing the temperature the \%IE decreased due to desorption of extract molecules from the metal surfaces takes place.

The study of the activation parameters reveals that the activation energy $\left(E_{\mathrm{a}}\right)$ increases when the concentration of plant extract increases. To illustrate, the energy barrier of corrosion reaction increases, as a result, the corrosion rate decreases. Moreover, the interpretation of the values and positive sign of the enthalpies $\left(\Delta H^{*}\right)$ reflect the endothermic nature of corrosion process of carbon steel in hydrochloric acid solutions. On the other hand, the values of entropy $\Delta S^{*}$ pertinent to uninhibited and inhibited acid solutions are negative. This implies that the activated complex, in the rate determining step, accompanied by dissociation rather than association, meaning that
Table 3 Thermodynamic parameters for the adsorption process of Tilia cordata on carbon steel surface in $1 \mathrm{M} \mathrm{HCl}$ at different temperatures

\begin{tabular}{lllll}
\hline Temp. K & $K_{\text {ads }} \mathrm{M}^{-1}$ & $-\Delta G_{\text {ads }}^{\circ} \mathrm{kJ} \mathrm{mol}^{-1}$ & $-\Delta H_{\text {ads }}^{\circ} \mathrm{kJ} \mathrm{mol}^{-1}$ & $-\Delta S_{\text {ads }}^{\circ} \mathrm{J} \mathrm{mol}^{-1} \mathrm{~K}^{-1}$ \\
\hline 303 & 35 & 18.8 & 44.9 & 86.5 \\
313 & 16.6 & 16.9 & 44.9 & 89.6 \\
323 & 13.6 & 16.4 & 44.9 & 88.3 \\
333 & 6.2 & 14.5 & 44.9 & 91.5 \\
\hline
\end{tabular}




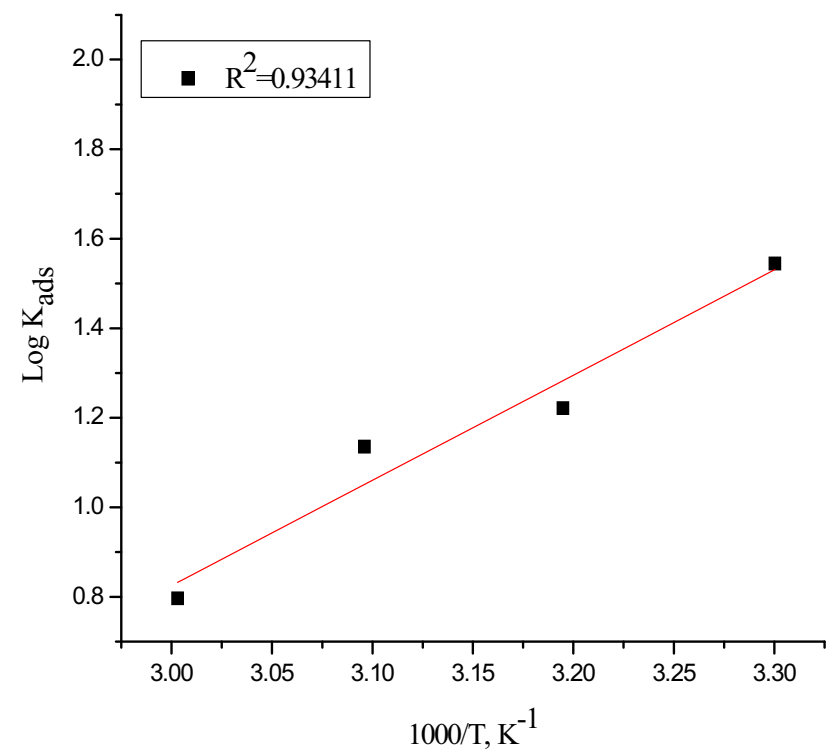

Fig. 3 ( $\log K_{\text {ads }}$ ) versus $(1000 / T)$ curve for the dissolution of carbon steel in $1 \mathrm{M} \mathrm{HCl}$ in the presence of Tilia cordata extract

disordering increases on going from reactants to the activated complex [32] (Fig. 4).

\section{Electrochemical measurements}

\section{Potentiodynamic polarization tests}

The kinetics of anodic and cathodic reactions was studied by Tafel polarization measurements. Figure 6 indicates the effect of addition of Tilia cordata on anodic and cathodic polarization curves of carbon steel in $1 \mathrm{M} \mathrm{HCl}$. Both cathodic and anodic reactions were noted to subsidize when the plant extract is added to the test solution, in turn, confirms that this additive reduced the metal dissolution and suppressed the hydrogen evolution reaction largely. Electrochemical corrosion kinetics parameters, i.e., corrosion potential $\left(E_{\text {corr }}\right)$, cathodic and anodic Tafel slopes $\left(\beta_{\mathrm{a}}\right.$, $\beta_{\mathrm{c}}$ ) and corrosion current density $\left(i_{\text {corr }}\right)$ obtained from the extrapolation of the polarization curves, are given in Table 5. The region between linear part of cathodic and anodic branch of polarization curves becomes wider when

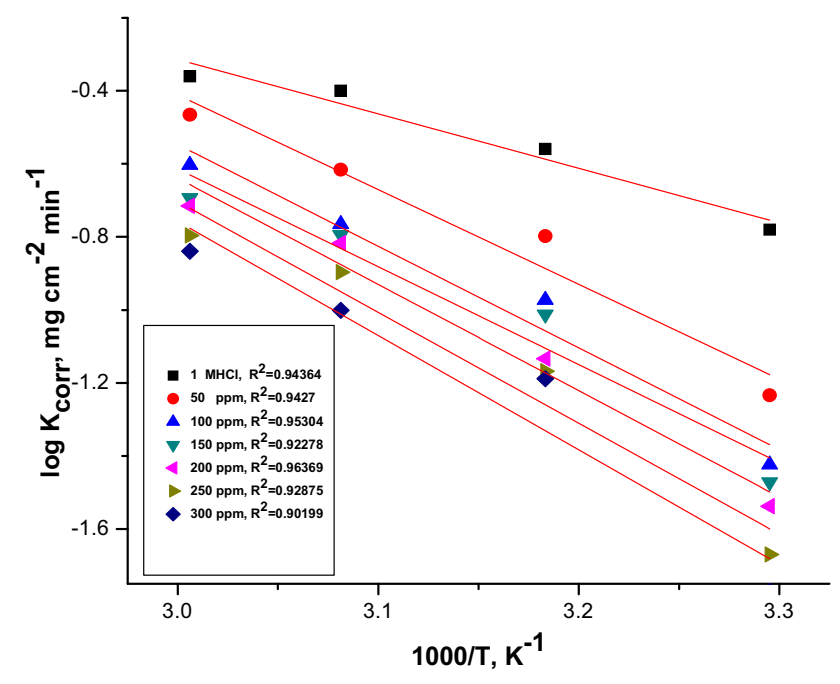

Fig. 4 ( $\log k_{\text {corr }}$ vs $1 / T$ ) plots for corrosion of carbon steel in $1 \mathrm{M}$ $\mathrm{HCl}$ in the absence and presence of different concentration of Tilia cordata extract

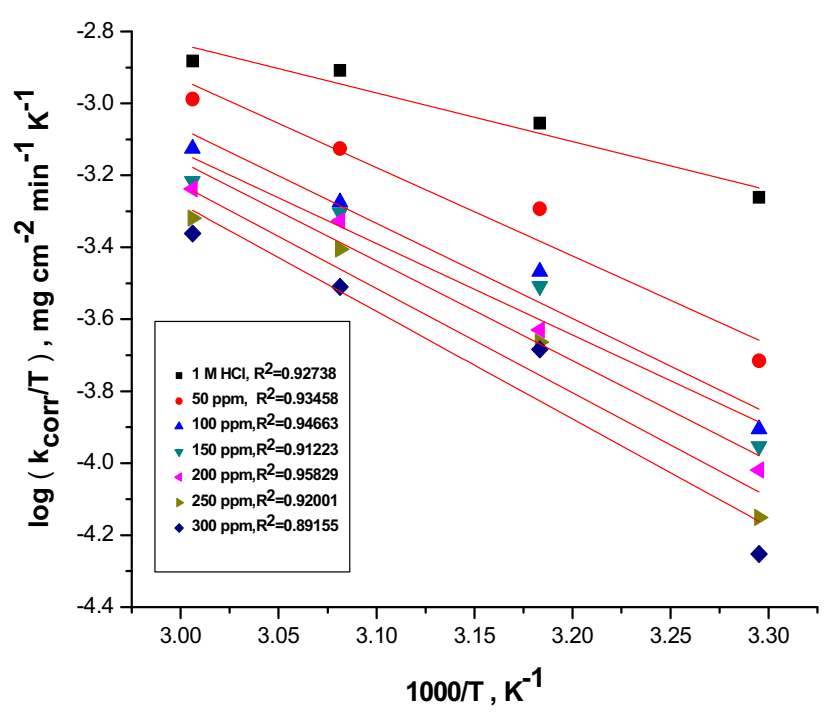

Fig. $5 \log \left(k_{\text {corr }} / T\right)$ vs $(1 / T)$ curves for corrosion of carbon steel in $1 \mathrm{M} \mathrm{HCl}$ in absence and presence of different concentration of Tilia cordata extract
Table 4 Activation parameters for corrosion of carbon steel in $1 \mathrm{M} \mathrm{HCl}$ in absence and presence of different concentration of Tilia cordata extract

\begin{tabular}{llll}
\hline$\left[C_{\mathrm{inh}}\right]\left(\mathrm{mg} \mathrm{L}^{-1}\right)$ & $E_{\mathrm{a}}{ }^{*} \mathrm{~kJ} \mathrm{~mol}^{-1}$ & $\Delta H^{*} \mathrm{~kJ} \mathrm{~mol}^{-1}$ & $-\Delta S^{*} \mathrm{~J} \mathrm{~mol}^{-1} \mathrm{~K}^{-1}$ \\
\hline 0 & 28.5 & 25.8 & 174.3 \\
50 & 49.7 & 47.0 & 112.6 \\
100 & 53.3 & 50.6 & 104.5 \\
150 & 51.3 & 48.6 & 111.7 \\
200 & 55.7 & 53.0 & 98.9 \\
250 & 58.1 & 55.4 & 92.9 \\
300 & 59.9 & 57.2 & 88.6 \\
\hline
\end{tabular}




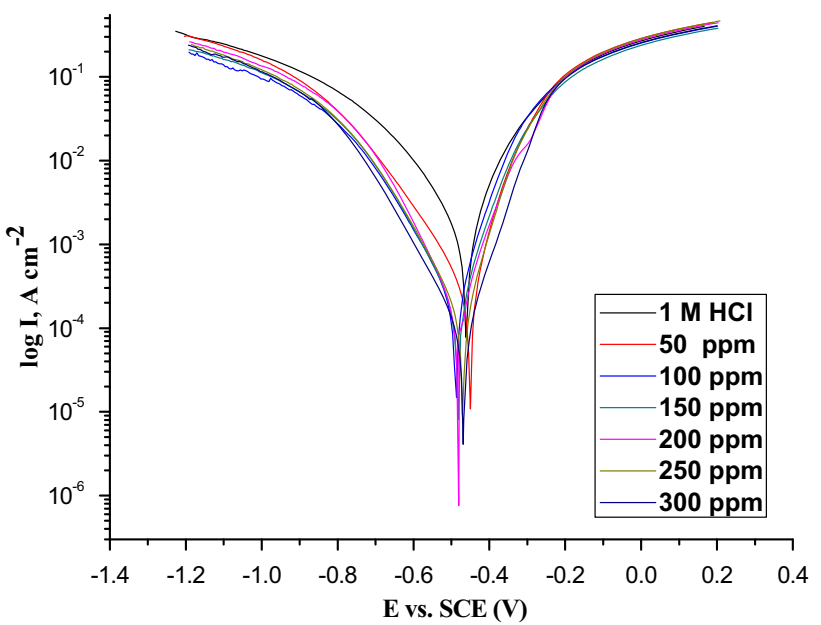

Fig. 6 Potentiodynamic polarization curves for the dissolution of carbon steel in $1 \mathrm{M} \mathrm{HCl}$ in the absence and presence of different concentrations of Tilia extract at $25{ }^{\circ} \mathrm{C}$

Tilia cordata extract is added to the acid solution $[33,34]$. The results recorded in Table 5 showed that the addition of the investigated extract lowers both cathodic and anodic currents without any significant change in corrosion potential. This indicates that this extract acts as mixed type inhibitors. The Tafel polarization results were consistent with those obtained from weight loss method. The surface coverage $(\theta)$ and inhibition efficiency (\% IE) were calculated from the below Eq. (8).

$\% \mathrm{IE}=\theta \times 100=\left[1-\left(i^{\circ} / i\right)\right] \times 100$,

where $i^{\circ}, i$ are the values of corrosion current density in the presence and absence of Tilia cordata extracts, respectively.

\section{Electrochemical impedance spectroscopy (EIS) tests}

The two main parameters, $R_{\mathrm{ct}}$ and $C_{\mathrm{dl}}$, deduced from electrochemical impedance techniques are listed in Table 6. Furthermore, Fig. 7 presents the Nyquist plots of carbon steel in uninhibited and inhibited test solution of $1 \mathrm{M}$ hydrochloric acid solution. The semicircular nature of impedance diagrams indicates that a charge transfer
Table 6 Data from electrochemical impedance measurements for corrosion of carbon steel in $1 \mathrm{M} \mathrm{HCl}$ solutions at various concentrations of Tilia cordata extract

\begin{tabular}{llll}
\hline$\left[C_{\mathrm{inh}}\right]\left(\mathrm{mg} \mathrm{L}^{-1}\right)$ & $R_{\mathrm{ct}}, \mathrm{Ohm} \mathrm{cm}^{2}$ & $C_{\mathrm{dl}}, \mu \mathrm{F} / \mathrm{cm}^{2}$ & $\% \mathrm{IE}$ \\
\hline 0 & 12.4 & 8.33 & - \\
50 & 155.4 & 5.28 & 92.0 \\
100 & 165.9 & 4.00 & 92.5 \\
150 & 195.6 & 3.87 & 93.6 \\
200 & 198.8 & 3.68 & 93.7 \\
250 & 209.6 & 3.64 & 94.0 \\
300 & 357.2 & 2.22 & 96.5 \\
\hline
\end{tabular}

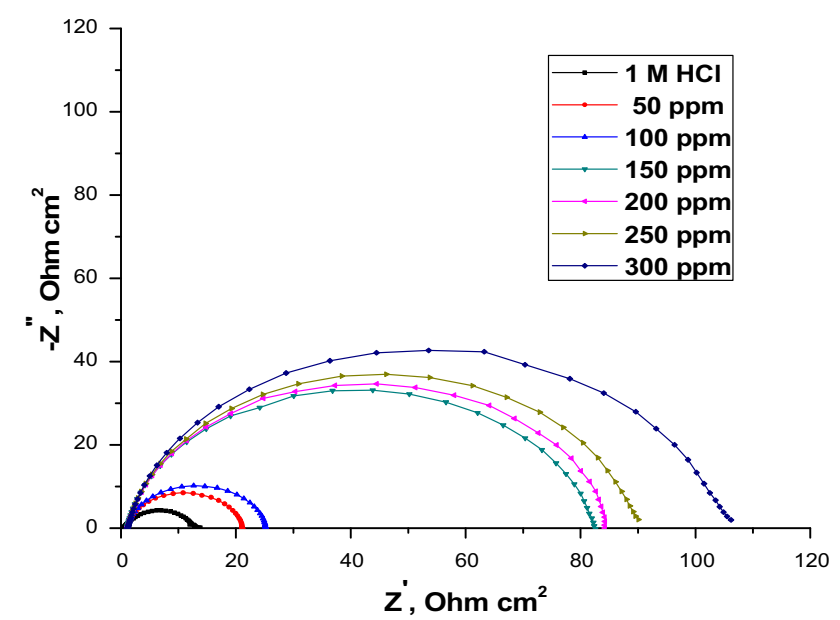

Fig. 7 Nyquist plots of carbon steel in $1 \mathrm{M} \mathrm{HCl}$ in absence and presence of different concentrations of Tilia extract at $25^{\circ} \mathrm{C}$

process mainly governs the corrosion of carbon steel, and the dissolution mechanism of carbon steel remains unaffected when the plant extract is added to the test solution [35] (Fig. 8). The experimental data were fitted to an equivalent electrical circuit, as shown in Fig. 9, so that the resultant spectra of the Nyquist plots impedance can be investigated. This simulation modeling assists to determine not only the solution resistance $R_{s}$, but also is useful for predicting other important parameters such as
Table 5 Potentiodynamic data of carbon steel in $1 \mathrm{M} \mathrm{HCl}$ in absence and presence of different concentrations of rosemary extract

\begin{tabular}{lccccccc}
\hline$\left[C_{\mathrm{inh}}\right]\left(\mathrm{mg} \mathrm{L}^{-1}\right)$ & $i_{\text {corr, }} \mu \mathrm{A} \mathrm{cm}^{-2}$ & $-E_{\text {corr }}, \mathrm{mV}$ & $\beta_{\mathrm{a}}, \mathrm{mV} \mathrm{dec}^{-1}$ & $\beta_{\mathrm{c}}, \mathrm{mV} \mathrm{dec}^{-1}$ & $k_{\text {corr }} \mathrm{mpy}$ & $\theta$ & $\% \mathrm{IE}$ \\
\hline 0 & 1750 & 461 & 119 & 195 & 801.1 & - & - \\
50 & 456 & 451 & 102 & 187 & 208.2 & 0.739 & 73.9 \\
100 & 274 & 489 & 89 & 147 & 125.2 & 0.843 & 84.3 \\
150 & 262 & 482 & 91 & 155 & 119.6 & 0.850 & 85.0 \\
200 & 251 & 481 & 100 & 143 & 114.7 & 0.856 & 85.9 \\
250 & 226 & 470 & 90 & 158 & 103.2 & 0.870 & 87.0 \\
300 & 124 & 468 & 86 & 147 & 56.6 & 0.929 & 92.9 \\
\hline
\end{tabular}


Fig. 8 Bode plot for corrosion of carbon steel in $1 \mathrm{M} \mathrm{HCl}$ in absence and presence of different concentrations of Tilia extract at $25{ }^{\circ} \mathrm{C}$

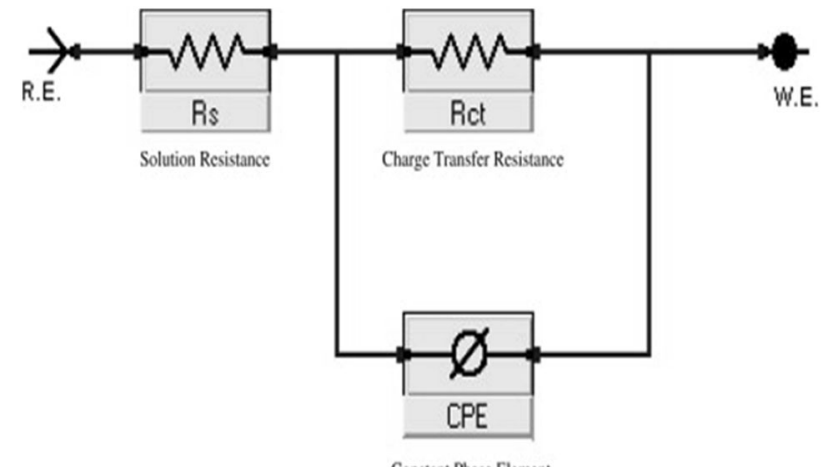

Constant Phase Element

Fig. 9 Equivalent circuit model fitting impedance spectra

the double layer capacitance $C_{\mathrm{dl}}$ and the charge transfer resistance $R_{\mathrm{ct}}$.

The values of charge transfer resistance $R_{\mathrm{ct}}$ were calculated from the difference in impedance at low and high frequencies obtained from Bode plots. The value of $R_{\mathrm{ct}}$ is considered a measure of electron transfer across the carbon steel surface and it is inversely proportional to the corrosion rate. The capacitance double layer $C_{\mathrm{dl}}$ was calculated at the frequency $f_{\max }$ at which the imaginary component of the impedance is maximal using the equation [36].

$C_{d l}=\frac{1}{2 \pi f_{\max } R_{c t}}$

The impedance results presented in Table 6 indicate that the magnitude of $R_{\mathrm{ct}}$ value increased while that of $C_{\mathrm{dl}}$ decreased with the addition of various concentrations of Tilia cordata to $1 \mathrm{M} \mathrm{HCl}$. The decrease in $C_{\mathrm{dl}}$ values results from the adsorption of the plant extract compounds at the metal surface. The double layer between the charged metal surface and the solution is considered as an electrical capacitor. The adsorption of plant extract on carbon steel surface reduces its electrical capacity as they replace the water molecules and other ions adsorbed at the interface surface leading to the formation of a protective adsorption layer on the metal (working electrode) surface which increases the thickness of the electrical double layer. The thickness of the protective layer $(d)$ is related to $C_{\mathrm{dl}}$ in accordance with Helmholtz model, given by the following equation [37]:

$C_{\mathrm{dl}}=\frac{\varepsilon \varepsilon_{o} A}{d}$

where $\varepsilon$ is the dielectric constant of the medium and $\varepsilon_{0}$ is the permittivity of free space $\left(8.854 \times 10^{-14} \mathrm{~F} / \mathrm{cm}\right)$ and $A$ is the effective surface area of the electrode. From Table 6, it is clear that as the thickness of the protective layer formed by inhibitor molecules, increases, the $C_{\mathrm{dl}}$ should decrease. In the present work $C_{\mathrm{dl}}$ value was found to reach the maximum in case of the uninhibited solution. Addition of Tilia cordata extract to the aggressive medium is found to decrease the $C_{\mathrm{dl}}$ value and also the lowest value was obtained for the investigated extract with the highest inhibition efficiency. The decrease in $C_{\mathrm{dl}}$ values on increasing the extract inhibitor concentration is due to building an adsorbed layer on interface surface between the metal and acid solution. The inhibition efficiency of extract inhibitor for the corrosion of carbon steel in $1 \mathrm{M} \mathrm{HCl}$ is calculated using $R_{\mathrm{ct}}$ values as follows:

$\% \mathrm{IE}=\theta \times 100=\left[1-\left(R_{\mathrm{ct}}^{\circ} / R_{\mathrm{ct}}\right)\right] \times 100$. 

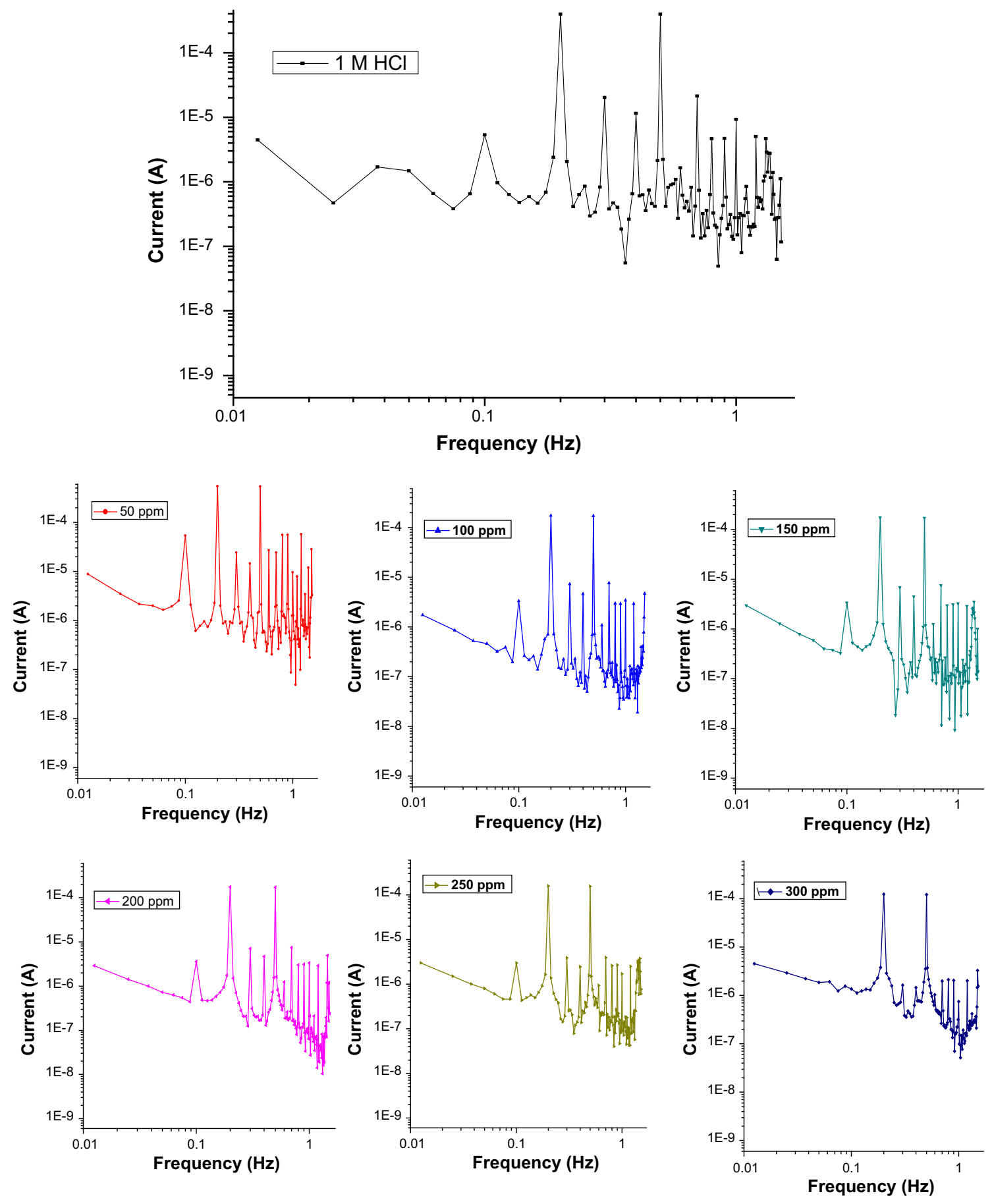

Fig. 10 EFM spectra for carbon steel in $1 \mathrm{M} \mathrm{HCl}$ in the absence and presence of $300 \mathrm{mg} / \mathrm{l}$ of Tilia extract at $25^{\circ} \mathrm{C}$

\section{Electrochemical frequency modulation measurements}

The current response, due to the potential perturbation by applying one or more sine waves, contains useful information about the corroding system. The larger peaks were used to calculate the corrosion current values without prior knowledge of Tafel slopes, and with only a small polarization signal $[38,39]$. The causality factors CF-2 and CF-3 are calculated from the frequency spectrum of the current responses. Figure 10 shows the EFM spectra (current vs frequency) of carbon steel in $\mathrm{HCl}$ solution in absence and presence of different concentrations of Tilia cordata extract. The corrosion current density decreases on increasing the concentration of Tilia cordata extract, indicating that this extract inhibits the corrosion of carbon 
Table 7 Electrochemical kinetic parameters obtained by EFM technique for carbon steel in $1 \mathrm{M} \mathrm{HCl}$ solution containing various concentrations of the Tilia cordata extract at $25^{\circ} \mathrm{C}$

\begin{tabular}{lllcccccc}
\hline$\left[C_{\text {inh }}\right]\left(\mathrm{mg} \mathrm{L}^{-1}\right)$ & $i_{\text {corr }} \mu \mathrm{A} \mathrm{cm}^{-2}$ & $\beta_{\mathrm{a} \mathrm{mV} \mathrm{dec}} \mathrm{m}^{-1}$ & $\beta_{\mathrm{c}} \mathrm{mV} \mathrm{dec}^{-1}$ & $k_{\text {corr }} \mathrm{mpy}$ & $\mathrm{CF}(2)$ & $\mathrm{CF}(3)$ & $\theta$ \\
\hline 0 & 655.7 & 92 & 131 & 299.6 & 2.06 & 3.56 & - \\
50 & 300.1 & 34 & 38 & 137.1 & 2.00 & 2.00 & 0.542 & 54.2 \\
100 & 233.8 & 79 & 100 & 106.8 & 1.86 & 2.29 & 0.643 & 64.3 \\
150 & 229 & 78 & 99 & 104.6 & 1.86 & 2.73 & 0.650 & 65.0 \\
200 & 226.4 & 78 & 97 & 103.5 & 1.81 & 2.58 & 0.654 & 65.4 \\
250 & 211.5 & 83 & 95 & 96.67 & 1.86 & 3.51 & 0.677 & 67.7 \\
300 & 176.3 & 89 & 97 & 80.55 & 1.63 & 3.78 & 0.731 & 73.1 \\
\hline
\end{tabular}

Fig. 11 SEM images of carbon steel surface a polished surface, b exposed to free acid solution only (blank) and c exposed to test solution containing $300 \mathrm{mg} / \mathrm{l}$ of Tilia cordata extract

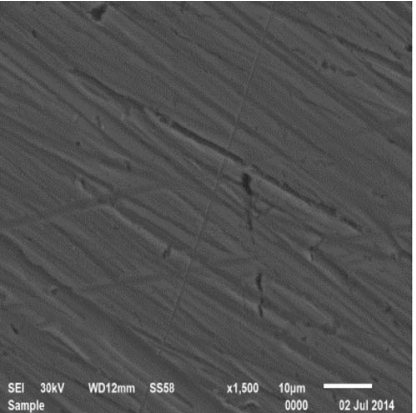

(a) polished surface

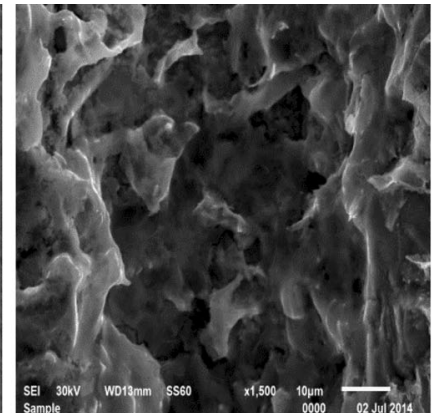

(b) exposed to free acid solution only (Blank)

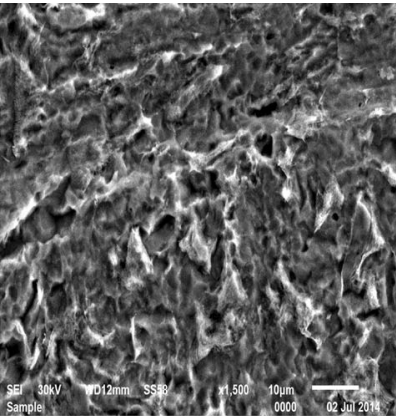

(c) exposed to test solution containing $300 \mathrm{mg} . \mathrm{L}^{-1}$ of Tilia cordata extract steel in $1 \mathrm{M} \mathrm{HCl}$ through forming a barrier film by adsorption onto the metal surface. The causality factors obtained under different experimental conditions are approximately equal to its theoretical values (2 and 3 ) indicating that the measured data are valid. The increase in Tilia cordata concentration accompanied by an increase in the inhibition efficiency and the inhibition efficiency was calculated using Eq. (12):

$\% \mathrm{IE}_{\mathrm{EFM}}=\left[1-\left(i_{\text {corr }} / i_{\text {corr }}^{\circ}\right)\right] \times 100$

where $i_{\text {corr }}$ and $i_{\text {corr }}^{\circ}$ are the corrosion current densities in absence and presence of Tilia cordata extract (Table 7).

\section{Scanning electron microscopy (SEM) studies}

Figure 11 represents the micrographs obtained for carbon steel samples before and after immersed into $1 \mathrm{M} \mathrm{HCl}$ for $12 \mathrm{~h}$, without, and with further treatment of plant extract additive. It can be shown that the carbon steel surface suffer from severe dissolution in case of exposure to the free acid. On the contrary, the surface of carbon steel is found to be less affected by the aggressiveness of the acid solution when exposed to $1 \mathrm{M} \mathrm{HCl}$ solution containing $300 \mathrm{mg} \mathrm{L}^{-1}$ of Tilia cordata extract. Besides, the morphology of carbon steel surface is apparently smooth compared to the micrograph obtained in case of the free acid. Moreover, a thin protective layer is formed and evenly distributed on carbon steel surface. This corroborates the involvement of plant extract molecules in blocking the corrosion cells on carbon steel surface by decreasing the contact between carbon steel surface and the corrosive solution that sequentially inhance the inhibition characteristics and show better corrosion protection for the metal surface [40, 41].

\section{EDX analysis}

The elemental composition of the thin film formed on carbon steel surface was analyzed using energy EDX. The results listed in Table 8 provide a comparison between the elemental compositions of carbon steel surface before and after $12 \mathrm{~h}$ exposure to the uninhibited and inhibited $1 \mathrm{M}$ hydrochloric acid solution. The EDX analysis indicates that the weight $\%$ of carbon is increased, that can be attributed to the carbon atoms of some adsorbed organic molecules, in case of the test solution containing $300 \mathrm{mg} \mathrm{L}^{-1}$ of Tilia cordata extract. This confirms the formation of protective layer, because of the adsorption of some organic constituents dissolved in the aqueous extract of Tilia cordata (Fig. 12). 
Table 8 Elemental composition (wt \%) of carbon steel surface after $12 \mathrm{~h}$. of immersion in $1 \mathrm{M} \mathrm{HCl}$ in absence and presence of $300 \mathrm{mg} \mathrm{L}^{-1}$ of Tilia cordata extract

\begin{tabular}{lllll}
\hline Wt $\%$ & Iron & Carbon & Silicone & Manganese \\
\hline Carbon steel surface & 87.72 & 11.59 & 0.38 & 0.76 \\
Free acid solution (Blank) & 82.06 & 16.66 & 0.26 & 0.74 \\
$300 \mathrm{mg} \mathrm{L}^{-1}$ of Tilia cordata & 80.45 & 18.40 & 0.35 & 0.81 \\
\hline
\end{tabular}

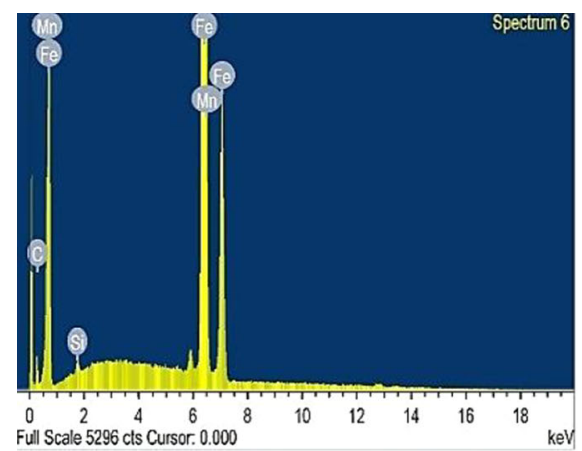

(a) polished surface

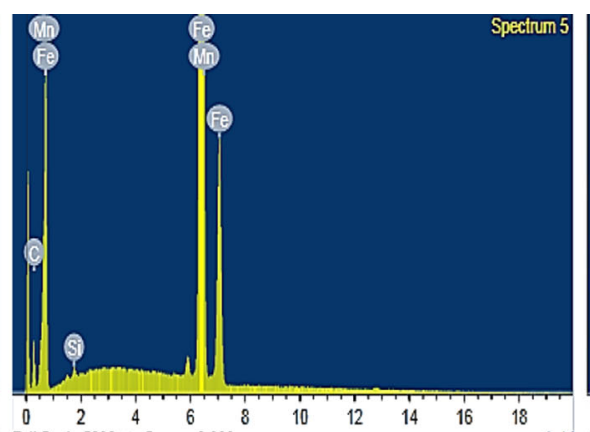

(b) exposed to free acid solution only (Blank)

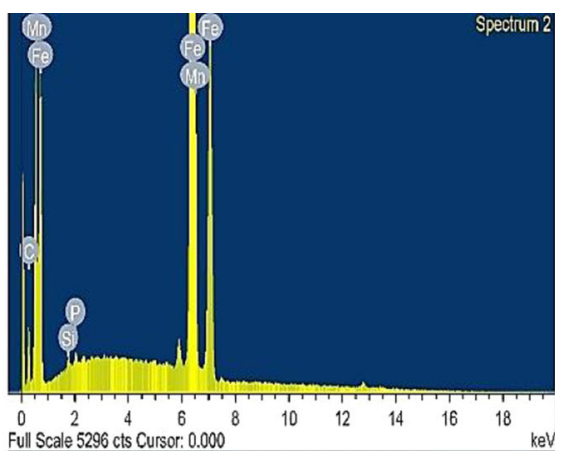

(c) exposed to test solution containing $300 \mathrm{mg} . \mathrm{L}^{-1}$ of Tilia cordata extract

Fig. 12 EDX analysis of carbon steel surface a polished surface, $\mathbf{b}$ exposed to free acid solution only (blank) and $\mathbf{c}$ exposed to test solution containing $300 \mathrm{mg} / \mathrm{l}$ of Tilia cordata extract

\section{Mechanism of inhibition}

However, it is not readily available at this point to determine the specific constituent or group of molecules of the plant extract that are adsorbed onto the metal surface, Tilia cordata exhibited a high content of flavonol $O$-glycosides (mono- and di-) quercetin and kaempferol derivatives and tiliroside. These constituents are adsorbed onto the metal surface, the adsorbed molecules constitute a physical barrier between the metal and the corrosion medium, thereby reducing the metal dissolution at anodic sites and hydrogen evolution at cathodic sites, also interfering the corrosive attack of acid solutions and protecting the metal surface. Tilia cordata extract provide greater inhibition due to the large degree of surface coverage resulting from the adsorption of particular molecules or a group of constituents from the crude extract [42].

\section{Conclusion}

The good accordance between the results obtained from different experimental methods leads to conclude that an aqueous extract of Tilia cordata can be used as an effective green corrosion inhibitor for the corrosion of carbon steel in hydrochloric acid solutions. The inhibition efficiency percentages increased with increasing the concentration of plant extract, but decreased with raising the test solution temperature. The free energy change of adsorption, enthalpy of adsorption and entropy of adsorption indicated that the adsorption process is spontaneous and exothermic and the phytochemical constituents of Tilia cordata extract adsorbed at the metalsurface interface and produce a protective barrier by the process of electrostatic adsorption (physisorption). The activation parameters reveal that the activation energy increases as the concentration of Tilia cordata increases. Furthermore, the endothermic nature of the carbon steel dissolution process can be inferred from the values of activation enthalpy. In addition, the entropy of activation increased with increasing inhibitor concentration; hence, the system disorder is increased.

\section{Compliance with ethical standards}

Conflict of interest The authors declare that they have no competing interests.

Open Access This article is distributed under the terms of the Creative Commons Attribution 4.0 International License (http://crea tivecommons.org/licenses/by/4.0/), which permits unrestricted use, distribution, and reproduction in any medium, provided you give appropriate credit to the original author(s) and the source, provide a link to the Creative Commons license, and indicate if changes were made. 


\section{References}

1. Fekry AM, Mohamed RR (2010) Acetyl thiourea chitosan as an eco-friendly inhibitor for mild steel in sulphuric acid medium. Electrochim Acta 55(6):1933-1939

2. Mitchell KE (1998) US Patent 5,746,908. U.S. Patent and Trademark Office, Washington

3. Gale WF, Totemeier TC, (Eds.) (2003) Smithells metals reference book. Butterworth-Heinemann, UK

4. Lalitha A, Ramesh S, Rajeswari S (2005) Surface protection of copper in acid medium by azoles and surfactants. Electrochim Acta 51(1):47-55

5. Anthony N, Malarvizhi E, Maheshwari P et al (2004) Corrosion inhibition by caffeine-Mn. $2+$ system. Indian. J Chem Technol 11(3):346-350

6. Benabdellah M, Hammouti B (2005) Corrosion behaviour of steel in concentrated phosphoric acid solutions. Appl Surf Sci 252(5):1657-1661

7. Elouafi M, Abed Y, Hammouti B et al (2001) Effect of acidity level on the corrosion of steel in concentrated $\mathrm{HCl}$ solutions. Ann Chim Sci Mater 26(5):79-84

8. Abed Y, Hammouti B (2000) Corrosion of steel in concentrated $\mathrm{H}_{2} \mathrm{SO}_{4}$ solutions. Bull Electrochem 16(7):296-298

9. Weina Su, Tian Yimei, Peng Sen (2014) The influence of sodium hypochlorite biocide on the corrosion of carbon steel in reclaimed water used as circulating cooling water. Appl Surf Sci 315(1):95-103

10. El-Etre AY (2006) Khillah extract as inhibitor for acid corrosion of SX 316 steel. Appl Surf Sci 252(24):8521-8525

11. Oguzie EE (2007) Corrosion inhibition of aluminium in acidic and alkaline media by Sansevieria trifasciata extract. Corros Sci 49:1527-1539

12. Fouda AS, Nofal AM, El-Ewady GY, Abousalem AS (2015) Ecofriendly impact of rosmarinus officinalis as corrosion inhibitor for carbon steel in hydrochloric acid solutions. Der Pharma Chemica 7(5):183-197

13. Fouda AS, El-Awady GY, Abousalem AS (2014) Corrosion inhibition and thermodynamic activation parameters of arcatium lappa extract on mild steel in acidic medium. Chem Sci Rev Lett 3(12):1277-1290

14. Li Yan, Zhao P, Liang Q et al (2005) Berberine as a natural source inhibitor for mild steel in $1 \mathrm{M} \mathrm{H}_{2} \mathrm{SO}_{4}$. Appl Surf Sci 252(5):1245-1253

15. Zucchi F, Omar IH (1985) Plant extracts as corrosion inhibitors of mild steel in $\mathrm{HCl}$ solutions. Surf Tech 24(4):391-399

16. Negri G, Santi D, Tabach R (2013) Flavonol glycosides found in hydroethanolic extracts from Tilia cordata, a species utilized as anxiolytics. Revista Brasileira de Plantas Medicinais 15(2):217-224

17. Karioti A, Chiarabini L, Alachkar A, Chehna MF, Vincieri FF, Bilia AR (2014) HPLC-DAD and HPLC-ESI-MS analyses of Tiliaeflos and its preparations. J Pharm Biomed Anal 100:205-214

18. Behrens A, Maie N, Knicker H, Kögel-Knabner I (2003) MALDI-TOF mass spectrometry and PSD fragmentation as means for the analysis of condensed tannins in plant leaves and needles. Phytochemistry 62(7):1159-1170

19. Oniszczuk A, Podgórski R (2015) Influence of different extraction methods on the quantification of selected flavonoids and phenolic acids from Tilia cordata inflorescence. Ind Crops Prod 76:509-514

20. Khaled KF (2008) Application of electrochemical frequency modulation for monitoring corrosion and corrosion inhibition of iron by some indole derivatives in molar hydrochloric acid. Mater Chem Phys 112(1):290-300

21. Khaled KF (2009) Evaluation of electrochemical frequency modulation as a new technique for monitoring corrosion and corrosion inhibition of carbon steel in perchloric acid using hydrazine carbodithioic acid derivatives. J Appl Electrochem 39(3):429-438

22. Bosch RW, Hubrecht J, Bogaerts WF et al (2001) Mobile hydrogen monitoring in the wall of hydrogenation reactors. Corrosion 57(1):60-71

23. Abdel-Rehim SS, Khaled KF, Abd-Elshafi NS (2006) Electrochemical frequency modulation as a new technique for monitoring corrosion inhibition of iron in acid media by new thiourea derivative. Electrochim Acta 51(16):3269-3277

24. Şahin M, Bilgiç S, Yilmaz H (2002) The inhibition effects of some cyclic nitrogen compounds on the corrosion of the steel in $\mathrm{NaCl}$ mediums. Appl Surf Sci 195(1-4):1-7

25. Schorr M, Yahalom J (1977) the significance of the energy of activation for the dissolution reaction of metal in acids. Corros Sci 12(11):867-868

26. Tang L, Lie X, Si Y et al (2006) the synergistic inhibition between 8-hydroxyquinoline and chloride ion for the corrosion of cold rolled steel in $0.5 \mathrm{M}$ sulfuric acid. Mater Chem Phys 95(1):29-38

27. Maayta AK, Al-Rawashdeh NAF (2004) Inhibition of acidic corrosion of pure aluminum by some organic compounds. Corros Sci 46(5):1129-1140

28. Abboud Y, Abourriche A, Saffaj T et al (2009) A novel azo dye, 8-quinolinol-5-azoantipyrine as corrosion inhibitor for mild steel in acidic media. Desalination 237(1-3):175-189

29. Khamis E (1990) the effect of temperature on the acidic dissolution of steel in the presence of inhibitors. Corrosion 46(6):476-484

30. Benabdellah M, Aouniti A, Dafali A et al (2006) Investigation of the inhibitive effect of triphenyltin 2-thiophene carboxylate on corrosion of steel in $2 \mathrm{M} \mathrm{H}_{3} \mathrm{PO}_{4}$ solutions. Appl Surf Sci 252(23):8341-8347

31. Khaled KF, Samardzija KB, Hackerman N (2004) Piperidines as corrosion inhibitors for iron in hydrochloric acid. J Appl Electrochem 34(7):697-704

32. Singh AK, Singh AK, Ebenso EE (2014) Inhibition effect of cefradine on corrosion of mild steel in $\mathrm{HCl}$ solution. Int J Electrochem Sci 9:352-364

33. Morad MS, El-Dean AK (2006) 2, 2'-Dithiobis (3-cyano-4, 6-dimethylpyridine): a new class of acid corrosion inhibitors for mild steel. Corros Sci 48(11):3398-3412

34. Singh AK, Quraishi MA (2010) Piroxicam; a novel corrosion inhibitor for mild steel corrosion in $\mathrm{HCl}$ acid solution. J Mater Environ Sci 1(2):101-110

35. Arab ST, Al-Turkustani AM (2006) Corrosion inhibition of steel in phosphoric acid by phenacyldimethylsulfonium bromide and some of its $p$-substituted derivatives. Portugaliae Electrochimica Acta 24:53-69

36. Elewady GY (2008) Pyrimidine derivatives as corrosion inhibitors for carbon-steel in $2 \mathrm{M}$ hydrochloric acid solution. Int $\mathrm{J}$ Electrochem Sci 3(9):1149-1161

37. Ahamad I, Prasad R, Quraishi MA (2010) Thermodynamic, electrochemical and quantum chemical investigation of some Schiff bases as corrosion inhibitors for mild steel in hydrochloric acid solutions. Corros Sci 52(3):933-942

38. Kus E, Mansfeld F (2006) An evaluation of the electrochemical frequency modulation (EFM) technique. Corros Sci 48(4):965-979 
39. Caigman GA, Metcalf SK, Holt EM (2000) Thiophene substituted dihydropyridines. J Chem Cryst 30(6):415-422

40. Muralidharan S, Phani KLN Pitchumani S et al (1995) Polyamino-benzoquinone polymers: a new class of corrosion inhibitors for mild steel. J Electrochem Soc 142(5):1478-1483

41. Prabhu RA, Venkatesha TV, Shanbhag AV et al (2008) Inhibition effects of some Schiff's bases on the corrosion of mild steel in hydrochloric acid solution. Corros Sci 50(12):3356-3362
42. Oguzie EE (2008) Corrosion inhibitive effect and adsorption behavior of Hibiscus sabdariffa extract on mild steel in acidic media. Port Electrochim Acta 26(3):303-314 